\title{
Mit Messer und Spraydose
}

\section{Erhard Taverna}

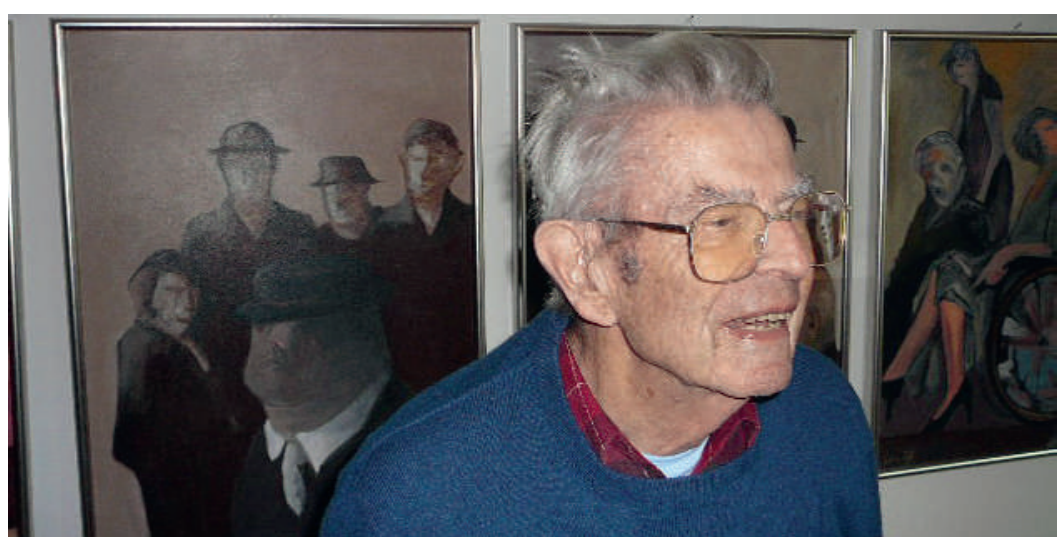

Hans Jörg Leu vor einigen seiner Werke.

In den weihnächtlichen Gassen von Baden spielt eine Jazzgruppe für die zahlreichen Passanten. Nebelfetzen streichen über die Dächer, während Hans Jörg Leu mit ausholenden Schritten ein Stadtoriginal seines Wohnorts beschreibt. Die eigene Berufsbiographie behandelt er heute als Nebensache. Staatsexamen

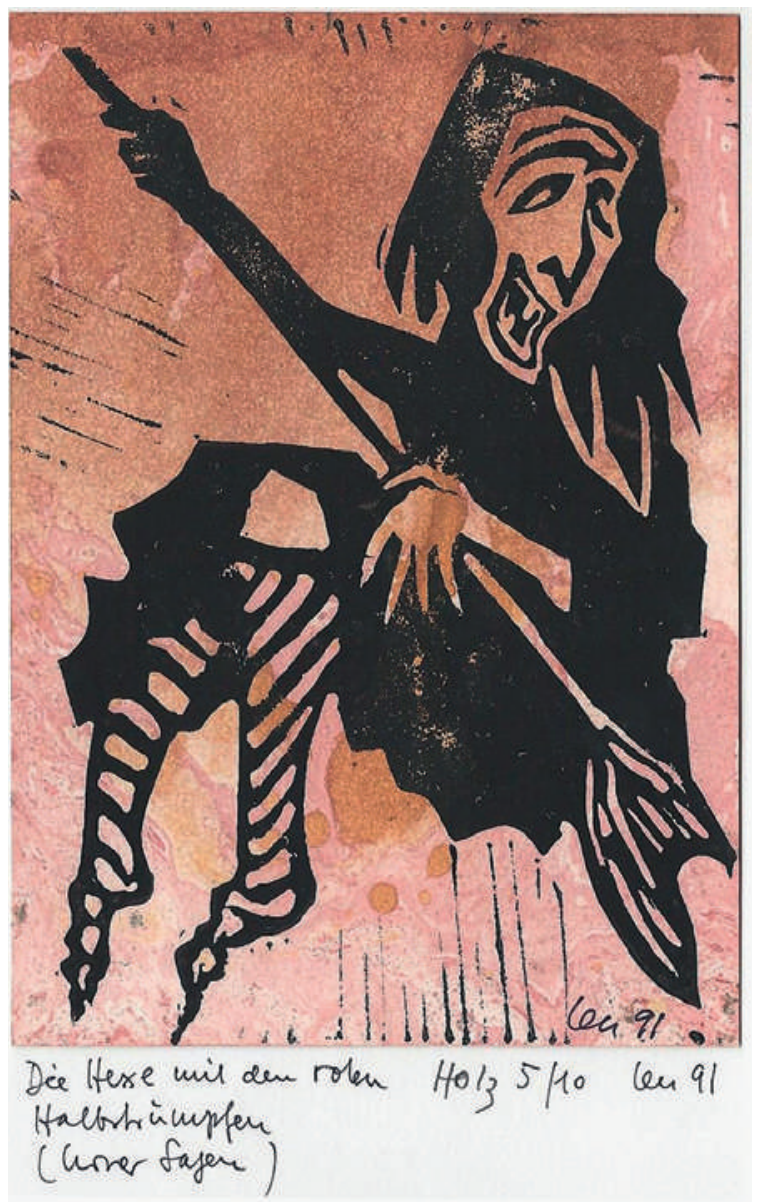

1951, einer der Schweizer Pioniere im Fach Angiologie, damals noch mit Lehrmeistern in Spanien, Holland, Österreich, Deutschland und Kalifornien. Titularprofessor an der Universität Zürich mit einer Praxis in Baden und jahrzehntelang Chefredaktor des European Journal of Vascular Medicine Vasa.

Tempi passati. Nach zwanzig Jahren in Novaggio (Malcantone), wo er immer noch mit seiner Ehefrau fast die Hälfte des Jahres verbringt, spricht Hans Jörg Leu lieber über seine künstlerischen Werke als über Gefässpathologien und frühere Forschungsprojekte. Zum Beispiel über die Kurzgeschichten, deren Anfänge auf das Fachmagazin mit seinen medizinischen Beiträgen, Editorials, Glossen und Satiren zurückgehen.

Er habe schon als Kleinkind viel gezeichnet, anfangs vom Musikdirektor-Vater und später als Autodidakt von befreundeten Kunstmalern gefördert. Ab vierzig malte er mit Öl und Acryl und begann mit Linol- und Holzschnitten zu experimentieren. Zuerst waren es

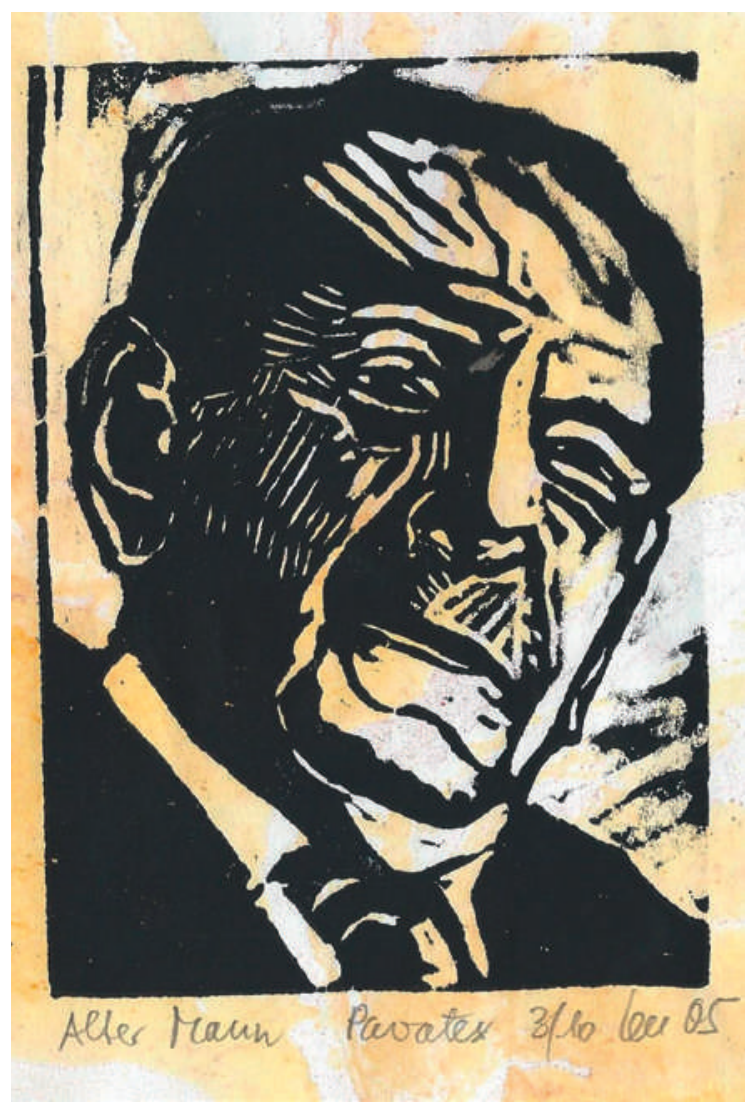

Zwei Holzschnitte: "Die Hexe mit den roten Halbstrümpfen» und "Alter Mann». 

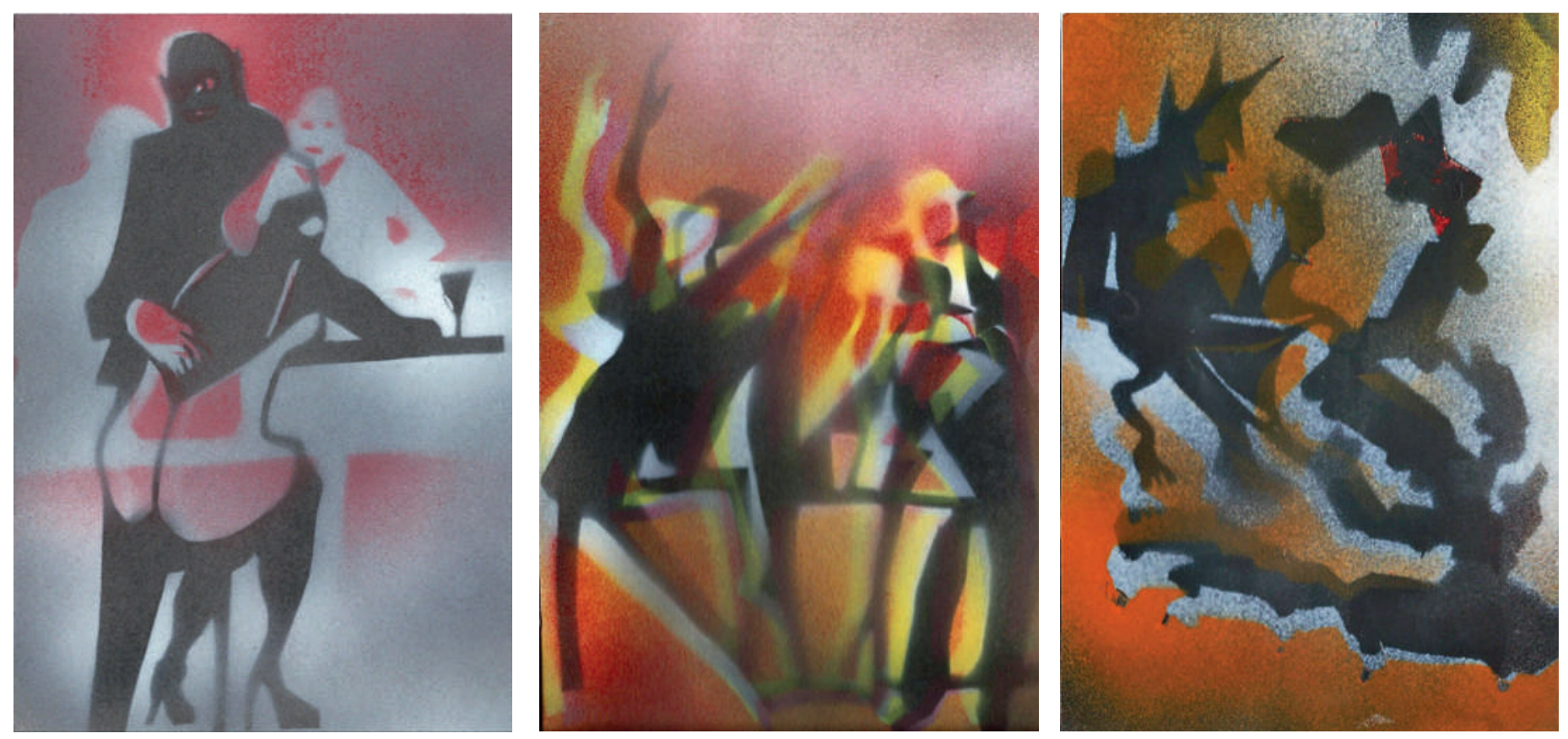

Spielerisch leicht, sinnlich und abstrakt wirken die bunten Spraybilder.

Karikaturen und Collagen für Fasnachts-Schnitzelbänke, später porträtierte er die Familie, Freunde und Künstler. Die vielen Bilder aus der Spraydose sind eine Art Hauswährung. Kinder und Enkel bedienen sich, Bekannte werden damit beschenkt und die Deutschlektorin aus Köln deckt sich als Gegenleistung damit ein. Das Curriculum listet zahlreiche ein-

\section{Ein falscher Schnitt und die Arbeit beginnt wieder von vorne.}

zelne und gemeinsame Ausstellungen auf, auch Bilder in öffentlichem Besitz und mehrere Buchillustrationen mit Linol- und Holzschnitten. Die Arbeit am Holz erfordert eine spiegelbildliche Darstellung in höchster Präzision. Ein falscher Schnitt und die Arbeit beginnt wieder von vorne. Sprachlich und bildlich beherrscht Leu die Reduktion, die scharf umrissene Darstellung eines komplexen Zusammenhangs, der erst durch die Auslassungen plastisch wird. Wo er seine Texte mit Holzschnitten illustriert, erzählt er gleichsam zwei sich ergänzende Geschichten. Der Leser und Betrachter interpretiert die Aus- sparungen zu einem Gesamtbild. Dabei wirken die Schwarz-Weiss-Motive ganz unterschiedlich. Einmal sind sie filigran-streng aber auch derb-wuchtig, sie erscheinen - flächig oder dreidimensional - übergangslos konturiert oder abgestuft unscharf, hell und dunkel, wie Tag und Nacht. Die Skala des Meisters umfasst viele Nuancen.

Spielerisch leicht, sinnlich und abstrakt wirken die vielen bunten Spraybilder. Schablonen, leicht verschoben oder übereinandergelegt, bewirken räumliche Tiefe und stimulieren die Fantasie des Betrachters. Es wirkt, als würden sich die beiden Arbeitsweisen ergänzen. Das Messer stellt andere Anforderungen als die Spraydose, exakt, monochrom und schnittgenau das eine, assoziativ, bunt und spielerisch das andere. So sieht es der Betrachter und bewundert Kopf und Hand, die auch in hohem Alter zielgenau und einfallsreich ein grosses Talent in Kunst umsetzen.

Tisch und Couch im Wohnzimmer unter den selbstgemalten Ölbildern sind mit Ordnern und Reproduktionen übersät. Die Ehefrau, frühere Kantonsrätin und exzellente Köchin, erinnert daran, dass auch die Kunst durch den Magen geht. 